\title{
A LEGISLAÇÃO DE LICITAÇÕES E CONTRATOS DA ADMINISTRAÇÃO PÚBLICA E OS DESAFIOS DA INDÚSTRIA
}

\section{ARTIGO ORIGINAL}

PEREIRA, Caio César Queiroz ${ }^{1}$

PEREIRA, Caio César Queiroz. A legislação de licitações e contratos da administração pública e os desafios da indústria. Revista Científica Multidisciplinar Núcleo do Conhecimento. Ano 06, Ed. 05, Vol. 04, pp. 132-148. Maio de 2021. ISSN: 2448-0959, Link de acesso:

https://www.nucleodoconhecimento.com.br/administracao/licitacoes-e-contratos, DOI: 10.32749/nucleodoconhecimento.com.br/administracao/licitacoes-e-contratos

\section{RESUMO}

O presente artigo tem o objetivo de elucidar as práticas e os desafios do processo de compras públicas dentro de uma indústria do segmento de saúde sob controle total do Governo Federal. Neste trabalho serão apresentadas as principais particularidades, do processo de compras públicas regidas pela Lei Federal n. 8.666 de 21 de Junho de 1993, que Regulamenta o art. 37, inciso XXI, da Constituição Federal, instituindo normas gerais de licitações e contratos da Administração Pública, além de outras legislações posteriores e que direta ou indiretamente interferem no dia a dia da Organização. Será apresentado o caso baseado no Instituto de Tecnologia em Imunobiológicos (Bio-Manguinhos) que é uma unidade da Fundação Oswaldo Cruz (Fiocruz) responsável pelo desenvolvimento tecnológico e pela produção de vacinas, reativos e biofármacos voltados para atender prioritariamente às demandas da saúde pública nacional. Apesar de não ser comum dentro do Governo Federal, BioManguinhos é uma organização produtiva e que possui todas as características de

1Pós Graduado em Gestão Pública, Bacharel em Administração.

RC: 84709

Disponível em: https://www.nucleodoconhecimento.com.br/administracao/licitacoes-econtratos 
indústria, contando com maquinários, pessoal, inputs (materiais a serem transformados), materiais em processo de transformação e outputs (materiais finais transformados) que fazem parte do processo e do ciclo produtivo do Instituto. Para atender as demandas de materiais, mobiliário, equipamentos, serviços e outros dentro do Instituto devem ser observadas pela área de compras as Legislações atinentes às compras públicas, o que ainda atualmente constitui-se em um processo lento, burocratizado e extremamente dependente de fundamentações legais e técnicas. Estas características possuem impacto direto nas diferentes áreas da organização, passando principalmente pelos setores produtivos e de manutenção, ocasionando algumas vezes parada ou atraso de produção e consequentemente dificuldade no atingimento de metas, resultados e objetivos. Destaca-se que o atual modelo de compras ao qual são submetidos os Órgãos Públicos no Brasil não foi criado pensando em organizações industriais, mas pensando no conceito geral de Órgão Público que é caracterizado por uma organização composta por agentes públicos que integra a estrutura da Administração com o objetivo de pôr em prática a vontade do Estado através de competências previamente definidas e cuja finalidade principal é o atendimento a coletividade visando o bem comum.

Palavras-Chave: Indústria, Legislação, Licitações, Compra, Instituto.

\section{INTRODUÇÃO}

O trabalho desenvolvido baseia-se primeiramente na legalidade que envolve 0 processo de compras públicas. Os pré-requisitos envolvem principalmente aspectos constantes nas diferentes legislações incidentes sobre o procedimento. Talvez o principal princípio que incide ao processo licitatório esteja no art. 37 da Constituição Federal de 1988, estamos falando do princípio da Legalidade. Este princípio é fundamento próprio do Estado de direito, devemos lembrar ainda que como citam Pinheiro Madeira e Moraes Mello (2014) em sua obra lei n. 8.666 Comentada e 
Interpretada o princípio em questão é citado não apenas no Art. 3ํ da lei de licitações, como também no Art. $4^{\circ}$ devido sua grande relevância para o tema.

Serão abordados os principais impactos no dia a dia da organização industrial em função especialmente da legalidade, dos prazos, e dos processos e procedimentos realizados pela área de compras. Evidentemente o estudo busca elucidar os desafios do profissional de compras, bem como de que forma a área pode solucionar situações e questões, que de certa forma influenciam no processo produtivo dos materiais gerados pela organização.

Foi identificado que as Leis que afetam o processo de compras públicas são determinantes para a principal questão deste artigo, que envolve principalmente a questão da organização industrial e o seu dia a dia, sendo esta impactada pelas legislações.

As legislações incidentes possuem impacto direto nos prazos de entrega, e no processo de compras em si, além disso uma ferramenta importante que pode minimizar estes impactos é o correto planejamento de necessidades de materiais sejam eles de consumo ou mesmo materiais usados no processo de produção.

O objetivo geral do Artigo é identificar os principais impactos do processo de compras sob a legislação pública na organização industrial ora analisada, identificando os pontos críticos que influenciam no dia a dia da instituição e a forma como isso afeta o cronograma de produção e entrega dos materiais frutos do processo produtivo de BioManguinhos.

O objetivo específico do estudo visa encontrar soluções aplicadas ao setor de compras que permitam a organização cumprir o cronograma de produção, e de entregas de produtos finais de modo que os impactos decorrentes do processo de compras influenciado pela legislação incidente sejam amenizados direcionando as 
diferentes áreas a convergência no cumprimento dos objetivos e metas de curto, médio e longo prazo.

\section{REVISÃO BIBLIOGRÁFICA}

De acordo com Horvath (2011) as contratações públicas de obras, compras, serviços entre outros conforme preceituado pelo Art. 37, XXI, da Constituição Federal de 1988 devem ser realizadas através do procedimento de Licitação. O processo licitatório nada mais é do que a demonstração para os interessados de que a Administração Pública busca realizar suas aquisições, em geral existem duas fases para a licitação, a fase interna e a fase interna, a fase interna inicia-se com a verificação da necessidade de aquisição, a elaboração da especificação do que se deseja adquirir, a definição da modalidade de compra de acordo com a legislação, e a elaboração do instrumento convocatório, ou edital. A fase externa tem início com a publicação do instrumento convocatório para o público em geral, seguida da realização do certame, a contratação da empresa fornecedora e enfim a execução do fornecimento do objeto desejado.

Neste sentido destacamos que na organização analisada todos os dispositivos legais para a realização das aquisições devem ser seguidos à risca, por estarmos tratando de uma organização pública vinculada a União, e a utilização de recursos públicos oriundos do tesouro nacional.

Segundo Pinheiro Madeira e Moraes Mello (2014), O princípio da legalidade é essencial as organizações públicas, desta forma este princípio vinculado ao processo licitatório é regramento básico a ser observado em todas as fazes do procedimento para aquisição de bens e serviços, ou seja, o Estado está vinculado a legislação de forma permanente.

A literatura é vasta no que tange as áreas do Direito Administrativo e das aquisições por órgãos públicos, porém é praticamente nula quando se trata dos procedimentos

RC: 84709

Disponível em: https://www.nucleodoconhecimento.com.br/administracao/licitacoes-econtratos 
de licitação em organização pública com característica industrial, uma vez que no geral são pouquíssimas as organizações públicas com este aspecto.

Independentemente do que trata a atual literatura, o caso concreto ora analisado põe em cheque especialmente os desafios encontrados no dia a dia da organização industrial da Administração Pública, fazendo um pequeno comparativo com as organizações industriais da iniciativa privada, desta forma vemos clara e evidente a questão da dificuldade de se tocar um grande complexo fabril com toda a legislação federal de compras públicas por trás dos panos, e que deve ser rigorosamente observada em todos os procedimentos internos e externos da organização. Estas questões dificultam o dia a dia da instituição e mostram a complexidade e desafios relativos ao trabalho do setor de aquisições desta organização, que deve focar-se nos aspectos jurídicos e legais de seus procedimentos.

\section{PROBLEMA INVESTIGADO}

A investigação acerca do tema consiste em analisar, identificar e propor melhorias para o processo de compras públicas sob a ótica de uma organização industrial. Neste caso, será abordado o caso concreto do Instituto de Tecnologia em Imunobiológicos - Bio-Manguinhos, Unidade componente da Fundação Oswaldo Cruz, vinculada ao Ministério da Saúde, Governo Federal, responsável pela produção de vacinas, reativos e biofármacos voltados para atender às demandas da saúde pública nacional. Ou seja, a instituição possui papel fundamental no processo de imunização da população, além de atender ainda outros países com o fornecimento de vacinas para atendimento da população dessas localidades.

A questão principal envolve o setor de compras de Bio-Manguinhos, responsável pela aquisição de materiais consumíveis e ainda de inputs que serão usados no processo produtivo e que gerarão os outputs, ou seja os produtos modificados que serão usados no processo de imunização da população em todo o território nacional e ainda em outros países que possuem relações diplomáticas e parcerias estratégicas nas

RC: 84709

Disponível em: https://www.nucleodoconhecimento.com.br/administracao/licitacoes-econtratos 
questões envolvendo saúde pública, tais como Angola, Moçambique entre outros, especialmente no continente africano.

O tema em questão, não possui uma abordagem ampla por parte de outros autores, uma vez que apenas alguns casos bastante específicos, bem como são casos práticos de pequenas organizações industriais com vinculação ao Estado.

Matias Pereira (2010), aborda em sua obra Manual de Gestão Pública Contemporânea, a questão do novo modelo de gerencialismo público que visa especialmente o foco no resultado, isto aplicado ao setor de compras de uma instituição pública permite que os profissionais atuantes nesta área trabalhem com objetivos previamente definidos, prazos e metas a serem cumpridas, estas questões envolvidas a uma organização industrial e com participação estratégica na saúde pública nacional proporciona uma melhor mensuração do trabalho e envolve a possibilidade de reduzir as falhas e os prazos já muito extensos nos processos de compra de uma instituição do governo, e ainda de característica industrial.

Outra questão de suma importância a ser analisada é que na Administração Pública não há espaço para exceções. Ou seja, todos os processos e procedimentos devem estar estritamente pautados na legislação, não há margem para que se deixe de fazer o correto, uma vez que caso haja qualquer tipo de ilegalidade todo o processo fica sujeito a anulação, podendo perder totalmente os efeitos por ele produzidos devido ao afastamento da legalidade. É importante frisar também que os servidores responsáveis pelos processos, podem ser penalizados caso seja comprovado que estes agiram fora dos limites legais, seja para benefício próprio ou de terceiros. O que se põe é que antes do objetivo da organização em si, deve estar o Interesse Público, a grande diferença entre as organizações privadas e públicas é que no setor privado é característica, natural e constante a busca pelo lucro, pelo resultado, o que muitas vezes especialmente no Brasil deixa de lado a questão ética e moral. Enquanto no setor público o objetivo principal é o interesse público, este deve estar diretamente ligado as questões éticas e morais, especialmente para os servidores que manejam o

RC: 84709

Disponível em: https://www.nucleodoconhecimento.com.br/administracao/licitacoes-econtratos 
processo dentro dessas instituições, a presunção de legitimidade é característica ímpar dos trabalhadores públicos o que pressupõe que estes devem sempre agir visando o interesse coletivo e a legalidade processual.

Levando-se em consideração o processo de compras da instituição e conforme já citado, toda a questão legal que envolve o mesmo, enfrenta-se ainda diariamente as questões urgentes e inadiáveis que impactam o dia a dia da indústria. Podemos citar um exemplo claro que é a quebra de maquinário necessário para o processo produtivo. Fazendo um comparativo, em uma organização industrial da iniciativa privada caso uma determinada máquina deixe de funcionar por questões de ordem técnica a solução pode ser simples e rápida. Basta entrar em contato com determinada empresa com know-how para o conserto deste maquinário que em pouco tempo o mesmo estará funcionando perfeitamente. Já nas instituições públicas estas ações não são possíveis, toda e qualquer empresa que vá fornecer bens ou serviços para órgãos do governo, devem seguir os tramites licitatórios constantes na Lei n. 8666 de 1993 e demais legislações, o que pode demandar muito mais tempo. Ou seja, o fundamental nestes casos é o Planejamento.

A legislação de compras aplicada aos órgãos federais, especialmente a Lei n. 8666 de 1993, trata especialmente dos processos licitatórios, porém neste mesmo texto são expostas outras formas de aquisição de bens e serviços diferentes da regra, que é licitar. Essas outras formas de aquisição, chamadas de modalidades podem ser realizadas através de dispensas, ou compras diretas e de Inexigibilidade de licitação. A legislação supracitada traz como regra, a licitação e a mesma legislação expõe em seus artigos os casos específicos em que a legislação não deve ser feita. Um dos principais artigos de que trata destas outras formas de legislação é o Art. 24, que traz em seus mais de trinta artigos, casos específicos em que o processo licitatório é dispensável, ou seja não é necessária sua realização. Um dos incisos mais utilizados nos processos de compras públicas se refere aos valores. O Inciso II do Artigo 24 da Lei n. 8666 de 1993 expõe em seu texto que as aquisições de bens e serviços de 
valores até oito mil reais, podem ser realizados através de compra direta. Isto ocorre tendo em vista que o custo indireto da realização da licitação, que envolve abertura de processo de compras, homem hora, publicações, contratos, custo com a emissão de documentos, tempo para conclusão e etc., não supriria o valor da aquisição em si. Ou seja, são valores considerados de pequeno vulto e por isso não compensaria a realização da licitação, sendo as dispensas por valor, mais rápidas e práticas.

Além da possibilidade de realização das compras nos moldes do Artigo 24, ou seja as dispensas, o Artigo 25 traz uma outra peculiaridade, a Licitação tem como um dos principais pontos gerar a competitividade entre as empresas e desta forma estimular a economia, os negócios e a geração de empregos. Mas existem alguns casos em que não existe a competitividade entre duas ou mais empresas, neste caso 0 artigo 25 traz a possibilidade da aquisição através de um processo chamado inexigibilidade de licitação.

Em suma, o texto diz: "É inexigível a licitação quando houver inviabilidade de competição, em especial: I - para aquisição de materiais, equipamentos, ou gêneros que só possam ser fornecidos por produtor, empresa ou representante comercial exclusivo..." Em outras palavras os agentes públicos responsáveis pelas aquisições do governo podem comprar diretamente de empresas que detém exclusividade no fornecimento de determinados bens e serviços a nível nacional não necessitando assim, da realização do processo licitatório. Nestes casos, o agente público e a empresa devem possuir todo o embasamento e enquadramento legal para que 0 processo de aquisição seja realizado desta forma, estando ambos, agente público e empresa sujeitos a penalidades nos casos em que ficar comprovada a ilegalidade na aquisição.

Todos estes casos evidenciam as dificuldades encontradas na indústria ora analisada, questões estas que envolvem principalmente aspectos de legalidade constantes nas mais diferentes normas aplicadas as compras públicas e que devem ser seguidas a risca por todos os servidores e trabalhadores, o aspecto do interesse público também

RC: 84709

Disponível em: https://www.nucleodoconhecimento.com.br/administracao/licitacoes-econtratos 
deve ser estritamente seguido e observado como fator preponderante para atuação dos agentes envolvidos, devemos destacar também que uma das grandes formas de resolução dos problemas pode estar no correto planejamento das demandas da organização, o que possibilitaria a adoção de estratégias direcionadas ao atendimento das necessidades, analisando cada caso com o objetivo de sanar os desvios e as não conformidades. Isto possibilitaria resultados mais próximos dos níveis de excelência, uma vez que o atendimento de todo o planejamento torna-se impossível de chegar ao prefeito, tendo em vista a instabilidade e os fatores externos e os fatos supervenientes que influenciam neste cenário.

\section{METODOLOGIA}

A pesquisa para a coleta de dados referente a este estudo envolve profissionais atuantes no setor de compras da organização sob análise e outros envolvidos direta ou indiretamente neste processo. Os envolvidos respondem a questionário de pesquisa para a coleta de dados e sugerem ações para a melhoria dos procedimentos. Estas sugestões propostas por integrantes de diferentes cargos e diversas áreas distintas contribuem para o levantamento e a apresentação de propostas que visem o objetivo macro de reduzir os impactos que afetam o setor de compras. Devemos destacar ainda que a principal queixa observada na coleta de dados é referente a morosidade, lentidão e burocracia até a finalização do processo de compra realizado na instituição, insto se deve especialmente a engessada legislação e a falha no planejamento das necessidades de materiais e produção, especialmente no que se refere aos prazos e especificações dos itens demandados.

Para a elaboração deste Artigo, será utilizada a metodologia do estudo bibliográfico de obras, artigos e leis, além da realização de pesquisas na internet. Paralelamente serão realizadas entrevistas com os gestores e colaboradores da organização que participam direta ou indiretamente do processo de compras do Instituto de Tecnologia em Imunobiológicos (Bio-Manguinhos) para obter informações acerca do assunto, e 
captando o máximo de opiniões e sugestões com o objetivo de identificar soluções para as questões aqui analisadas.

\section{BUSCA E ANÁLISE DE RESULTADOS}

Com base em pesquisas realizadas através de pesquisa com gestores e colaboradores das áreas envolvidas, identificou-se que no geral a melhor maneira de contribuir com a Instituição visando principalmente a redução do tempo de compra de materiais e serviços é através de um trabalho intenso de planejamento de materiais. É importante destacar que atualmente a organização conta com as Seções de Planejamento e Controle de Materiais (SEPCM) e Planejamento e Controle da Produção (SEPCP). Estes setores são diretamente ligados a Divisão de Planejamento Logístico (DIPLO) que por sua vez é subordinada ao Departamento de Logística (DELOG) da organização. Os envolvidos no processo de compras identificaram que atualmente um dos maiores motivos pelo qual ocorre atraso no processo de compras é devido a ajustes recorrentes nas especificações dos materiais demandados. Observou-se que os setores requisitantes ao demandarem seus materiais não especificam corretamente aquilo que desejam adquirir, isto em conjunto com a já engessada legislação de compras e suas burocracias representa um "delay" significativo no processo de aquisição como um todo.

Tomando como exemplo o Setor de Compras Nacionais (SECOM) da já citada instituição, o processo de compras se inicia com identificação da necessidade de aquisição de materiais dos setores requisitantes. Estes setores ao identificarem a necessidade de aquisição colocam seus pedidos de compra para os setores de planejamento SEPCM ou SEPCP, estes por sua vez verificam se os itens estão ou não cadastrados no sistema, e em seguida elaboram o pedido de compras que é repassado ao setor de aquisições nacional SECOM.

Neste ponto, em se tratando de uma aquisição no setor público, a doutrina atual deve ser analisada e seguida, no campo em questão deve-se levar em consideração a

RC: 84709

Disponível em: https://www.nucleodoconhecimento.com.br/administracao/licitacoes-econtratos 
motivação do ato, este regramento legal encontra-se nos artigos $2^{\circ}$ e 50 da Lei $n$. 9.784/99, a decisão para contratação necessita acima de qualquer coisa pairar sob o prisma do interesse público, o que é demonstrável a partir da motivação ou justificativa do ato da contratação. Neste sentido podemos citar as lições de Di Pietro (2005):

Entendemos que a motivação é, em regra, necessária, seja para os atos vinculados, seja para os atos discricionários, pois constitui garantia de legalidade, que tanto diz respeito ao interessado como à própria Administração Pública; a motivação é que permite a verificação, a qualquer momento, da legalidade do ato, até mesmo pelos demais poderes do Estado. Note-se que no artigo 111 da Constituição Paulista inclui a motivação entre os princípios da Administração Pública; do mesmo modo, o artigo $2^{\circ}$ da Lei 9.784 , de 29-1-99, que disciplina o processo administrativo federal, prevê a observância desse princípio, e o artigo 50 indica as hipóteses em que a motivação é obrigatória. (DI PIETRO, 2005, p. 204-205.)

Ao receber o pedido o SECOM através de seus analistas de compras busca orçamentos para referencias de preços dos itens que serão adquiridos. Após a obtenção da média de preços é verificada a modalidade de aquisição podendo ser via compra direta, cotação eletrônica, pregão tradicional ou através do sistema de registro de preços. Definida a modalidade de compra é solicitada pelo SECOM a reserva financeira ao Departamento Financeiro (DIFIN). Após o bloqueio da verba para aquisição dos materiais demandados, o setor de compras trabalha na montagem do processo de compras juntando todos os documentos necessários a constar nos autos, providenciando as autorizações e assinaturas necessárias a motivação dos atos e elaborando os Termos de Referência e editais, que posteriormente são remetidos a análise jurídica da Procuradoria Federal para emissão de parecer conclusivo sobre a legalidade e a continuação ou não da pretensa aquisição. Após a emissão do parecer da Procuradoria Federal, o processo retorna ao Analista de Compras que providencia a resposta aos apontamentos elucidados, e prossegue com a aquisição através da modalidade predefinida. Caso a modalidade adotada seja o Pregão Comum ou SRP alguns aspectos legais devem ser estritamente observados e cumpridos, como por exemplo os referentes ao princípio da publicidade, tratado especialmente pelo art. 17 do Decreto n. 5.450, de 31 de maio de 2005. Após finalizado o processo de compra, RC: 84709

Disponível em: https://www.nucleodoconhecimento.com.br/administracao/licitacoes-econtratos 
o setor ou unidade requisitante recebe a informação da conclusão do processo pelo setor de compras que encaminha o processo ao Setor de Gestão de Fornecedores (SEGEF) que realiza o acompanhamento das entregas de materiais ou da prestação dos serviços contratados, fiscalizando os fornecedores e estreitando o relacionamento entre ambos os lados. Este cenário representaria a perfeição do processo, mesmo com todos os percalços encontrados ao longo do caminho.

Deve-se esclarecer, porém que o cenário perfeito infelizmente ainda é raridade na organização, os prazos podem sofrer grandes variações de tempo, especialmente atrasos devido as questões de planejamento e burocracia incidentes no terreno da aquisição sob a égide da Legislação de Licitações e Contratos da Administração Pública. Isto, porém, não impede que as necessidades de materiais sejam melhores planejadas especialmente pelos setores demandantes de forma a considerar os prazos que afetam direta ou indiretamente o processo de compras na Instituição.

Muito mais simples seria se as aquisições na organização fossem tal como ocorre nas organizações da iniciativa privada, em geral muito mais rápidas, simples e desburocratizadas, ocorre que a instituição ora analisada se utiliza de recursos oriundos do tesouro, ou seja, provenientes do Ministério da Saúde, Governo Federal, desta forma é fundamental de acordo com as legislações que haja transparência na utilização das verbas públicas.

\section{DISCUSSÃO DOS RESULTADOS}

Observou-se no estudo em questão que para um melhor andamento da organização industrial, é fundamental o correto planejamento das necessidades de materiais, para uso ou para produção, sua demanda por serviços, e suas necessidades sempre intensas e constantes. Obviamente não se pode prever todas as necessidades e demandas que serão requisitadas ao longo do ano, porém é claro e evidente que questões voltadas ao correto planejamento e descrição de materiais e serviços, contribuiria de forma significativa com o setor responsável pelas aquisições.

RC: 84709

Disponível em: https://www.nucleodoconhecimento.com.br/administracao/licitacoes-econtratos 
É importante destacarmos que há neste meio de compras governamentais diversas mudanças em razão do advento de novas legislações, regulamentos e instruções normativas que frequentemente impactam no dia a dia das organizações.

Como exemplo podemos destacar a inovação trazida no mês de setembro de 2019, houve importante mudança nos rumos das compras públicas no País. A legislação regulamentadora do Pregão Eletrônico (Decreto n. 5.450 de 31 de maio de 2005) obteve significativa alteração em seu conteúdo.

Após diversos debates acerca do assunto, e da óbvia necessidade de mudança e atualização no cenário das compras públicas em 20 de setembro de 2019 foi assinado e publicado pelo Presidente da República Jair Messias Bolsonaro o Decreto 10.024 de 2020. Esse decreto representou um marco na atualização dos normativos referentes as compras públicas especialmente na esfera Federal.

Tal regulamentação trouxe entre diversas grandes mudanças principalmente na dinâmica de disputa e na participação das empresas fornecedoras, as grandes parceiras do Poder Público nacional.

Dentre as principais modificações podemos citar a possibilidade de orçamento sigiloso, tal previsão consta no Artigo 15 do novo Decreto. Esta previsão permite aos órgãos da Administração Pública ao publicarem os seus editais de Pregão Eletrônico para atendimento a suas demandas, omitir o valor de referência, ou estimado do certame. Tal caráter confere entre outros ganhos maior poder de barganha à Administração Pública, uma vez que no Decreto prévio (5.450 de 2005) obrigava-os a divulgar os valores de referência, fazendo com que as empresas licitantes, soubessem o limite de preços a ser pago pelos órgãos governamentais. Com o advento do novo Decreto e a possibilidade do caráter sigiloso, as empresas participantes, estas não sabendo os valores limites a serem aceitos, tem a possibilidade de maiores descontos, ocasionando no geral, maiores descontos, e menores preços a serem pagos pelos órgãos governamentais.

RC: 84709

Disponível em: https://www.nucleodoconhecimento.com.br/administracao/licitacoes-econtratos 
Outra grande inovação que podemos citar é a possibilidade de adoção de dois novos modos de disputa, quais sejam: Modo de Disputa "ABERTO" e "ABERTO E FECHADO". Estas novas ferramentas, foram objeto de intenso debate entre autoridades governamentais e representantes da iniciativa privada, especialmente após diversas queixas destes em função do até então utilizado "encerramento aleatório".

O antigo encerramento aleatório consistia período de tempo de 0 a 30 minutos o qual o sistema encerrava a fase de lances aleatoriamente, definindo como vencedor do certame o detentor do menor preço no momento deste do fechamento aleatório.

Com a possibilidade de utilização do modo de disputa aberto os licitantes presentes enviam lances sucessivos via sistema. Após o transcurso do tempo mínimo de 10 minutos e partir do $8^{\circ}$ minuto, a oferta de lances prorroga o tempo de disputa por 2 minutos. A disputa se encerra somente quando não há mais lances a serem ofertados por nenhum dos licitantes, o que elimina de vez o fenômeno "sorte" inerente ao antigo encerramento aleatório. Com esta nova ferramenta os órgãos governamentais obtêm efetivamente o menor preço praticado pelo mercado. Todavia, há um aspecto negativo nesta questão, que envolve a possibilidade de grande extensão durante muito tempo.

No que se refere ao Modo de disputa aberto e fechado o tempo é pré-determinado em 15 minutos. Em seguida, há um tempo aleatório de até 10 minutos, após o qual o sistema convidará de maneira automática o licitante classificado com o menor lance oferta e todos aqueles cujos valores estejam em até $10 \%$ acima do melhor lance. Tais empresas terão a possibilidade de apresentar em até 3 minutos um novo valor final e fechado. Caso não haja pelo menos 3 ofertas enquadradas na margem de $10 \%$, o sistema fará a convocação das melhores propostas respeitando o limite de 3 , para a proposta final e fechada em até 3 minutos. Podemos destacar a maior celeridade do sistema, embora neste caso possamos retroceder no tocante a economia esperada e obtida.

RC: 84709

Disponível em: https://www.nucleodoconhecimento.com.br/administracao/licitacoes-econtratos 
O referido Decreto, trouxe diversas outras inovações de maior ou menor importância dentro das instituições públicas, além é claro de impactar também diversos outros setores da economia que interagem diretamente com as organizações governamentais, seja atuando como fornecedor já consolidado, seja atuando como futuro novo parceiro, tendo em vista que o processo de aquisição existente no país, defende constitucionalmente a Ampla concorrência no mercado.

Outra inovação foi o momento da apresentação da documentação de habilitação de modo que a necessidade de apresentação da habilitação ocorre no momento em que o licitante cadastra sua proposta. O principal objetivo é conceder maior celeridade reduzindo a existência do chamado "licitante coelho" que oferta o menor preço, deixando de encaminhar a documentação exigida na sequência.

Tais inovações embora de grande valia, afetam diretamente o dia a dia das organizações governamentais, exigindo especialmente dos profissionais da área de compras, constantes atualizações, e principalmente estudo as novas diretrizes que constantemente trazem necessidade de atualização. Além do impacto direto no interior dos órgãos governamentais, tais mudanças também afetaram as empresas participantes das licitações públicas.

Em 2020, outra inovação foi trazida pela Instrução Normativa 73/2020. Publicada em 06 de agosto de 2020, a chamada "IN de pesquisa de preços" versa a respeito do procedimento administrativo para a realização de pesquisa de preços para a aquisição de bens e contratação de serviços em geral, no âmbito dos órgãos da administração pública federal. Embora esta, trate-se de legislação de menor impacto, vez que em sua maior parte refere-se apenas as atividades dos órgãos e não dos fornecedores, coube mais uma vez aos profissionais de compras públicas, estudo e compreensão de novas diretrizes para um dos procedimentos mais basilares e críticos do processo de compras governamentais. É sabido por toda a comunidade deste meio da razão da pesquisa de preços ser um dos grandes transtornos na elaboração de um orçamento adequado as compras realizadas.

RC: 84709

Disponível em: https://www.nucleodoconhecimento.com.br/administracao/licitacoes-econtratos 
É importante destacar que preços obtidos através de pesquisas de preço furadas podem acarretar em grandes prejuízos para a administração pública, seja em função de valores superestimados, seja devido a obtenção de valores subestimados.

No primeiro caso, uma pesquisa elaborada sem o devido cuidado e sem a adoção de critérios bem fundamentados, pode ocasionar em processos de aquisição e contratação realizados com valores acima do mercado, concluindo assim processos cujo superfaturamento por vezes gera grande prejuízo ao erário público, e severas punições aos gestores de recursos, e profissionais de compras.

Já no caso de processos subestimados o perigo reside principalmente na elaboração de orçamentos furados, os quais resultam em licitações fracassadas, seja por motivo de certames desertos, ou seja, quando não acudirem interessados na sua participação, seja por meio de altos valores ofertados pelas empresas participantes.

Embora haja constante inovação no meio, e estas visem e objetivem maior eficiência das compras públicas, deve-se mensurar também o impacto no dia a dia das organizações e instituições públicas no Brasil. Some-se a isto a peculiar característica das atividades realizadas no contexto órgão aqui abordado.

Há ainda intenso debate a respeito do Projeto de Lei $(P L)$ 4.253/2020, que visa criar um novo marco legal em substituição a já obsoleta Lei de Licitações (Lei n. 8.666 de 1993), a Lei do Pregão (Lei n. 10.520 de 2002) e ainda o Regime Diferenciado de Contratações. Embora neste caso já tenhamos passado do momento de uma atualização legal, devemos ressaltar sempre o impacto nas organizações públicas e privadas, bem como fomentar o amplo debate na sociedade brasileira, objetivando sempre primar pela lisura, transparência, constitucionalidade e igualdade que a atual conjuntura brasileira e mundial exigem.

Atualmente nos mais diversos setores governamentais todos adaptam-se as novas realidades em função de uma natural exigência legal, tecnológica e operacional, 
embora seja de suma importância, tais inovações requerem grande debate e contextualização dos impactos no dia a dia das organizações, especialmente aquelas em que a característica e atividade principal pouco assemelha-se a ideia de órgão público no Brasil.

Em um país ainda extremamente marcado pelo alto índice de corrupção em todas as esferas governamentais, dispositivos legais em constante atualização conferem maior transparência, eficiência e eficácia seja as instituições públicas e privadas, seja a sociedade como um todo, conferindo sempre um papel importante no sistema democrático atual. Nesta seara deve-se levar em consideração em processos de aquisição pública em primeiro lugar a legalidade, condição indispensável para todo e qualquer procedimento licitatório público, destacada com primazia por Di Pietro.

À Administração só é dado o direito de agir de acordo com o determinado pela lei. Este é o principal corolário do princípio da legalidade e "constitui uma das principais garantias de respeito aos direitos individuais (DI PIETRO, 1999, p.67)

Independentemente de toda a burocratização do processo em si, as questões que envolvem principalmente legalidade, além de outros princípios fundamentais como economicidade, moralidade que por si só já representam uma grande lentidão nos processos de aquisição da organização. Estas questões porém não devem ser levadas como justificativa para todos os atrasos que ocorrem no procedimento de compras e na contratação de serviços, muitas das vezes ocorrem situações alheias as vontades internas dos membros da organização responsáveis pelo processo de compras, como por exemplo a necessidade de autorização e coleta de assinatura de membros de alto escalão hierárquico inclusive dentro do Governo Federal, bem como o prazo para órgãos de controle tal como a Procuradoria Federal, que fica encarregada da análise jurídica de todos os procedimentos realizados em Bio-Manguinhos. 


\section{CONSIDERAÇÕES FINAIS}

O principal objetivo deste estudo foi identificar os problemas existentes na organização que incidem especificamente no setor de compras da instituição em análise, e ainda levantar possíveis alternativas que possam colaborar para que os desvios existentes nesta área e na organização como um todo sejam minimizados, de modo que os objetivos organizacionais sejam atingidos em sua totalidade.

Evidentemente tratamos de uma organização com características bastante peculiares e que foge a regras encontradas na maioria das organizações industriais no Brasil. $O$ caso concreto de Bio-Manguinhos trata-se de uma organização industrial, que visa atender especificamente as demandas do Sistema Único de Saúde, o SUS, e ainda contribuir com as questões de saúde pública nacional, através de programas de vacinações.

Esta organização trabalha no seu dia a dia como uma organização industrial, contendo um conceituado parque fabril de referência internacional, porém devido ao seu enquadramento todo o processo de compras e aquisições está intimamente pautado e balizado nas legislações federais de compras. Estas legislações as quais a organização está submetida ao serem elaboradas tiveram sua concepção baseada na visão de órgãos, repartições e instituições públicas brasileiras, que fundamentam toda sua organização, estrutura e direção nos aspectos legais, especialmente nos princípios da Legalidade, Impessoalidade, Moralidade, Publicidade e Eficiência. Não devemos descartar, porém o princípio do Devido Processo Legal, ao qual todas as organizações públicas devem observar.

Estas questões e características em questão provocam lentidão e excesso de burocracia especialmente nas aquisições realizadas na organização, portanto, a partir do estudo em questão, foi identificado que não se pode de forma alguma ignorar os aspectos legais dos processos de compras na instituição, de forma que a melhor maneira de reduzir custos, prazos e atender os objetivos organizacionais é através de

RC: 84709

Disponível em: https://www.nucleodoconhecimento.com.br/administracao/licitacoes-econtratos 
um bem estruturado planejamento das necessidades de materiais, sejam estes para consumo, utilizados na produção ou mesmo utilizados na manutenção de equipamentos e sistemas.

A partir de um planejamento de consumo bem definido e com foco nas demandas reais da organização e não apenas em histórico passado, podemos colaborar de modo a reduzir os principais problemas internos, contribuindo sobretudo para o pleno atendimento das demandas da instituição e da população, uma vez que um dos principais objetivos de Bio-Manguinhos é atender as demandas do Sistema Único de Saúde, bem como as demais demandas da população no âmbito da Saúde Pública do Brasil.

\section{REFERÊNCIAS}

CARVALHO FILHO, J. D. S. Manual de Direito Administrativo. 28. ed. São Paulo, SP, Atlas, 2015.

CONSTITUIÇÃO FEDERAL DE 5 DE OUTUBRO DE 1988. (1988). Constituição da República Federativa do Brasil. Brasília, DF. Recuperado de http://www.planalto.gov.br/ccivil_03/constituicao/constituicaocompilado.htm

DI PIETRO, M. S. Z. Direito Administrativo.11a ed. São Paulo, SP: Atlas, 1999.

DI PIETRO, M. S. Z. Direito Administrativo - 18ª ed. São Paulo, SP: Atlas, 2005.

HORVATH, M. V. F. Direito Administrativo, Barueri, SP: Manole, 2011.

LEI, n. 8.666, de 21 de junho de 1993. Regulamenta o art. 37, inciso XXI, da Constituição Federal, institui normas para licitações e contratos da Administração Pública e dá outras providências. Brasília, DF. 1993. Recuperado de http://www.planalto.gov.br/ccivil_03/Leis/L8666cons.htm.

RC: 84709

Disponível em: https://www.nucleodoconhecimento.com.br/administracao/licitacoes-econtratos 
LEI, n. 10.024, de 20 de setembro de 2019. Regulamenta a licitação, na modalidade pregão, na forma eletrônica, para a aquisição de bens e a contratação de serviços comuns, incluídos os serviços comuns de engenharia, e dispõe sobre o uso da dispensa eletrônica, no âmbito da administração pública federal. Brasília, DF, 2019. Recuperado de http://www.planalto.gov.br/ccivil_03/_ato20192022/2019/decreto/D10024.htm

MATIAS PEREIRA, J. Manual De Gestão Publica Contemporânea - 3ª edição, ed. São Paulo, SP: Atlas, 2010.

PINHEIRO MADEIRA, J. M. e de MORAES MELLO, C. Lei 8.666 Comentada e Interpretada - Lei de Licitação e Contratos Administrativos. Rio de Janeiro, RJ: Freitas Bastos, 2014.

Enviado: Fevereiro, 2021.

Aprovado: Maio, 2021. 